\title{
Multichannel customer management: The benefits and challenges
}

Received: 27th June, 2002

\section{Merlin Stone}

is IBM Professor of Relationship Marketing at Bristol Business School, Business Research Leader with IBM's business Innovation Services, and a director of QCi Ltd, Swallow Information Systems Ltd, The Database Group Ltd and ViewsCast Ltd. His consulting experience covers many sectors. He is the author of many articles and over 20 books on marketing and customer service, 'Up close \& personal - CRM @ work', Customer relationship marketing', 'Sucessful customer relationship marketing', 'CRM in financial services' and 'The management scorecard'. He is a founder member of the Institute of Direct Marketing, a Fellow of the Chartered Institute of Marketing and on the editorial advisory boards of many journals. He has a first class honours degree and doctorate in economics.

\section{Matt Hobbs}

is a principal consultant of the IBM Multi Channel Services Practice. With over a decade of experience in designing and implementing multichannel programmes for a variety of blue-chip clients he has contributed to many articles, books, seminars and conferences on the topic of multichannel customer management. Before joining IBM he was marketing director of the marketing strategy boutique Magenta Partnership, marketing manager of Demon Internet and managing director of his own consultancy. Matt is an active member of The Marketing Society, The Chartered Institute of Marketing and sits on the Marketing Council's e-commerce advisory board.

\section{Mahnaz Khaleeli}

is a managing consultant in the IBM Global Services' Insurance team. She has worked on engagements in strategy, knowledge management, e-business and business processes. Before joining IBM, she completed an MBA at Imperial College, University of London. Before this, she worked for five years at Lloyd's of London, where she led a variety of projects reviewing the operational and regulatory effectiveness of Lloyd's entities. While working for Lloyd's Mahnaz undertook the Chartered Institute of Marketing and Chartered Insurance Institute professional exams.

Abstract This paper defines multichannel customer management and investigates the opportunities and problems created by multichannel customer management. It explains why multichannel customer management has become an issue for serious discussion. Its aim is to help companies determine their strategies and tactics in this area. It does not provide a complete recipe for multichannel management, but rather explores the main decisions companies need to take as they add customer management channels. It identifies the importance of understanding customer needs and defining the experience customes wants from each channel and overall. It probes issues related to technology, organisation, measurement and economics. A checklist of questions to help companies examining this area is provided at the end of the paper.

Professor Merlin Stone Executive Consultant, Finance Sector, Business Innovation Services, IBM United Kingdom Ltd, 76 Upper Ground, South Bank, Mailpoint GSE 1, London SE1 9PZ, UK.

Tel: +44 (0)20 7202 3000; Fax: +44 (0)20 7202 5887; e-mail:

merlin_stone@uk.ibm.com

\section{INTRODUCTION - CHANGING TIMES, CHANGING CHANNELS}

It all used to be so simple - separate channel managers, separate segments targeted by separate channels, products aligned by channel, customers asked to deal with specific channels, measures of effectiveness purely on business transacted per channel. Things have, however, changed. Many companies are in a transition in channel management, typically covering the following:

- they are moving away from channels dedicated to restricted tasks and not communicating with each other, but 
are not certain how far to move towards channels which all work with the same data and to the same objectives

- they have seen some of the disadvantages of having different and possibly incompatible technology platforms for each channel, but are not certain of the benefits of moving to a single platform

- they have been through the process of setting up dot.coms as separate web channels

- separate web channels often had their own objectives, management, staff and systems, usually experienced escalating costs, provided a customer experience which was very different from that of other channels, and in some cases created brand damage and increased customer churn.

Companies are moving towards the world of multichannel integration. It is the purpose of this paper to investigate the meaning of multichannel customer management, and its benefits and challenges. For example, Forrester reports that 63 per cent of retailers and travel suppliers expect to use three or more channels by 2003. ${ }^{1}$ Furthermore, 37 per cent of European consumers are currently using the Internet channel to research products, with 85 per cent of this group buying offline the product they identified online. ${ }^{2}$

The purpose of this paper is to define multichannel customer management and to investigate the opportunities and problems created by multichannel customer management, and to help companies determine their strategies and tactics in this area. It does not provide a complete recipe for multichannel management, as the authors do not believe this can be done in just one paper. A checklist of questions to help companies examining this area is provided at the end of this paper.

\section{DEFINITION OF MULTICHANNEL CUSTOMER MANAGEMENT}

In this paper, a broad definition of the term 'multichannel customer management' is used, as follows:

multichannel customer management is the use of more than one channel or medium to manage customers in a way that is consistent and coordinated across all the channels or media used.

Note that the definition does not say 'the same way', as different channels may be best used for different tasks. For example, in a complex, technical, business-to-business environment, a sales person may be best for explaining the product, meeting objections and dealing with queries, and setting up initial contacts, while the Web or call centre might be used for reordering or checking progress with delivery. Also, it may be that channels are used in a differentiated manner, eg if a person wants to buy tickets for last-minute cancellations by other customers (anything from flights to equipment orders), they are referred to an auction website as other channels cannot support this kind of interaction cost-effectively.

Note too that for the purposes of this paper both distribution channels (through which products or services reach customers from suppliers, including transfer of title) and communication channels (through which customers and suppliers communicate with each other before, during and after distribution channels do their work), are included.

A multichannel strategy is one that provides numerous customer touch-points - the points at which 
products and services are purchased or serviced - across several distribution channels, such as:

- direct channels, eg telephone, Internet, mobile telephone (voice, SMS and eventually WAP) and interactive television (iTV)

- counter and kiosk service in branch networks or retail outlets

— partnerships and alliances

- sales force

- service force.

In some cases, these may be supported by broadcast media, in which the customer is not necessarily identified eg television, radio, press and some Web applications.

\section{WHY IS MULTICHANNEL CUSTOMER MANAGEMENT IMPORTANT NOW?}

There are two main reasons for the importance of multichannel customer management:

- developments in new channel technology: increasing reliability and speed of storage and telecommunications technology, convergence of voice, video and data

- customer requirements and expectations: some (not all) customers expect technology and processes to be used to manage them more consistently across channels.

Although it is now easier to ensure that every channel dealing directly with a given customer has the latest data on the state of interaction between supplier and customer, and follows related, connected processes, this is not costless or without technical problems. In particular, it should be noted that the companies for whom it is suggested that multichannel customer management will yield the most benefits are those for whom achieving it is most problematic. They have the largest customer bases, the most complex lines and the longest history of systems development, with many business-critical systems that support the process of customer management being quite old. This applies, for example, to many companies in financial services, logistics and manufacturing companies.

\section{THE BENEFITS}

The benefits of multichannel customer management, however, are numerous. These include benefits that work through customers, ones that work for customers and ones that work through efficiency, as follows.

The benefits that work through customers are:

- the identification and capture of opportunities for increasing value per customer

- increased convenience and an improved experience, reducing customer churn rates and increasing their motivation to buy more from the supplier

- the ability to leverage an established brand creating positive impacts on brand perception and mitigating the risk of brand damage, increasing the incentive for customers to stay and buy more.

The efficiency benefits are:

- increased efficiency through the sharing of processes, technology and information

- increased organisational flexibility

- increased efficiency in dealing with business partners, so they can reduce their costs 
— increased efficiency in exploiting customer data to identify customer needs, possibly indicating new paths for growth.

The benefits for customers are:

- increased choice in the way they can interact

- the ability to switch easily between the various channels, when it suits them and wherever they want to, depending on their preference and the type of interaction, whether it be the exploration or purchase of a product or service.

For the supplier, channel integration helps the sharing of customer data across channels to create a more complete customer profile which will help to maximise cross-selling opportunities.

\section{THE CHALLENGES}

Multichannel integration does not come without its challenges. Problems experienced by companies include:

- heavy investments in unconvincing multichannel strategies and technologies that result in a poor return on investment (ROI)

- problems in bringing together and standardising data about customers or resulting from interactions with them

- problems unifying different systems which may have very different data models

— difficulties in reducing or abolishing organisational boundaries.

For example, a survey of 50 retailers in the USA revealed that 48 per cent had learned nothing about their cross-channel customers and the biggest problem they faced was their inability to recognise known customers across all touch-points. ${ }^{3}$ Research to identify how far financial institutions have moved towards integrating customer touch-points was conducted by Forrester. ${ }^{4}$ They interviewed 50 information technology (IT) executives at banks, brokerages and insurance firms and found that for 52 per cent of the interviewees, channel integration projects were only just commencing, and for 54 per cent less than half of their products are integrated across channels.

Examples of organisations which have already gone some way towards integrating their channels include Allstate, Gateway and $E^{\star}$ Trade. All these organisations have invested hundreds of millions of dollars in building and integrating field, phone and Internet sales and service.

\section{SEVEN FACTORS DRIVING CHANGE}

Seven factors are causing companies to focus on multichannel management, as follows:

- customer demand

- channel costs

- strategic competitive advantage and differentiation

— allowing customers to manage relationships

- convergence of channel roles

- increased variety in customers' channel use patterns

— regulatory pressure.

\section{Customer demand}

Customers' desire for convenience has partly fuelled the increasing requirement for multichannel integration. Increased customer expectations translate to a demand for 24/7 high-speed access and choice in how they interact with a company. Customers often have strong 
preferences for using a specific channel for particular kinds of interaction, for example, they may use the in-store channel to commit to a buying decision, while using the more convenient online channel for exploring options - Forrester research identified that 46 per cent of online buyers research online to purchase offline, while 27 per cent research offline to buy online and 17 per cent do both. ${ }^{5}$ The focus should not be on providing all things in all channels but on providing the expected level of service for the target user group of that channel.

\section{Channel costs}

Maintaining channels (including marketing, advertising and managing the channels themselves) can typically account for around 40 per cent of a company's costs. Channels tend to be managed and maintained in silos with multiple infrastructures, management teams, technology and, possibly, different marketing strategies. The potential sharing and reuse of people, process and technology that can be achieved through an integrated channel strategy can, however, help improve an organisation's channel cost structure. Furthermore, the mapping of high-value customer usage and preferences can help identify channel areas of over-investment and channels which are not providing their optimum ROI and consequently identify channels that require some form of disinvestment and asset reallocation.

\section{Strategic competitive advantage and differentiation}

Products can be copied within days (H\&M, the fashion retailer, can copy a design from the catwalk and get it on the High Street within 72 hours). Pricing can be undercut within minutes. Apart from branding, multichannel management is one of the few customer-facing differentiators that can deliver true sustainable competitive advantage.

\section{Allowing customers to manage relationships}

Badly executed customer relationship management (CRM) (as, sadly, many CRM implementations are) can result in the organisation trying to control customers almost against their will through specific channels at specific times in the buying cycle. Customers can end up being made to feel like cattle being herded. Customer satisfaction and sales plummet. The term 'customer-managed relationships' (CMR) recognises the possibility of the customer being in control and the idea that it is the supplier's job to nurture and service the relationship.

\section{Convergence of channel roles}

Traditionally, channels were usually silos with most, if not all, of the functions required in the customer-buying cycle being fulfilled through one channel. Now in many companies, several channels are used during each customer-buying cycle and need to be designed, maintained and measured appropriately.

\section{Increased variety in customers' channel use patterns}

Those who synchronise their distribution channels will preserve or gain market share. Research has shown that multichannel shoppers in the financial services and retail sectors represent an increasingly large proportion of the attractive buying population. Furthermore, in the retail banking sector, multichannel customers 
are 25 to 50 per cent more profitable than those using one channel while retail shoppers who use multichannel purchasing spend two to four times more than those who purchase through a single channel. ${ }^{6}$ These findings are reinforced by the Boston Consulting Group whose research revealed that European retailers who have an off-line presence and manage an integrated Internet channel enjoy a disproportionate market-share and on-line satisfied customers spend 71 per cent more and transact $2 \frac{1}{2}$ times more than dissatisfied ones. ${ }^{7}$

Providing the target high-value multichannel customer segment with increased convenience through integrated channel management therefore not only encourages customer lock-on and brand loyalty, but results in improved customer lifetime value.

\section{Regulatory pressure}

In some sectors (eg financial services, public sector) government has a strong interest in the cost-effectiveness and quality of channel use, particularly where high channel costs lead to customers apparently getting poor value or even to customers being excluded or disenfranchised.

\section{DETERMINING CHANNEL FUNCTIONALITY}

Careful thought needs to be paid to the use of each channel in multichannel programmes - 'one channel fits all' is not the case anymore. Car buyers no longer just visit their local dealer, and television buyers no longer just go down to their local electrical store. Research shows that many customers use multiple channels throughout the buying cycle; some channels are used to research while others are used to purchase or service.

If a company decides to adopt a multichannel strategy, it must consider whether all its channels should offer the same range of products and services, and whether all channels should support all functionality areas. If necessary, one channel can perform all three functions, online retailers or bricks and mortar retail outlets for example.

It is essential to define the role of the various channels and how they interact. This helps identify and clarify the target customer usage and preferences. Gateway Computers is a good example of a company that defined distinct channel roles and tailored each to the needs of their targeted segments to meet customer preferences and optimise their multichannel revenues. ${ }^{8}$

\section{CUSTOMER EXPERIENCE MUST BE THE START POINT}

Customer experience should be the starting point for defining required channel functionality. Here are some suggestions as to how to build on it.

\section{Experiment with scenario planning}

It is vital to understand customers' channel preferences and usage. Customers not only want to buy, but may also need information and advisory tools. So, scenario planning can be used to understand which channels customers want to use for each part of the interaction process. Customer scenario planning is a powerful tool. It helps at all stages, from articulating the vision, determining processes and selecting technology. Thus, for expensive products customers may prefer to pre-shop online and then visit the store to look at the product and buy. For example, Charles Schwab, the financial services company, 
not only provides online, phone and in-person trading but also actionable information and advice through their online Learning Centre investment courses, online Portfolio Consultation and offline interactions. ${ }^{9}$

\section{Consistency}

Suppliers should plan for consistency of their brand, customer information and the customer experience across different channels. Scenario planning is also useful here. Channel synchronisation may be used to deliver a consistent customer experience. Consumers can become frustrated when suppliers' online channels only sell a selection of their offline products or services or altogether different products or services. Many suppliers, however, offer either the same or fewer product categories online as in other channels, and 58 per cent say that their sites offer a narrower assortment within those categories. ${ }^{10}$ There may, however, be very sound commercial reasons for this, eg delivery costs and the risk of customers making poor choices leading to high returns ratios. To improve consistency in the product/services offering, suppliers should stage online product roll-outs, first focusing on depth in their core product/services categories, then add breadth through new complementary products and finally, once the depth and breadth of products online reach critical mass, suppliers should introduce not-so-obvious categories and services both on and offline. Alternatively, the on and offline channels should be clearly positioned as different.

\section{Consistency in customer service and promotions}

Services and promotions can be integrated across channels. Companies can use various strategies to achieve this: merging mailing lists to target e-mail and catalogue promotions better; launching cross-channel loyalty programmes to increase customer retention; rewarding customers for whichever channel they complete their transaction within; and using bricks and mortar stores to provide local services to improve customer convenience for online shoppers. Examples of the latter include accepting returns in-store from online shoppers and offering in-store pick-up to get online shoppers to favour them. ${ }^{11}$ Where companies fail to integrate services and promotions across channels this will shift the balance of business elsewhere as customers' expectations are not met.

\section{Pricing}

In making the transition from single channel to multichannel, companies face the challenge of pricing issues, ie can they charge different prices to their customers for the same product online and offline? Many believe that different prices for the same product from the same company are not feasible; customers expect to be charged the same price whether purchasing online or offline, whether or not it is more cost effective for a supplier to sell online. The argument of suppliers is that a universal pricing strategy is not realistic, as offline customers must inevitably pay a premium for the added satisfaction of the in-store shopping experience. ${ }^{12}$

Research has been conducted into pricing efficiency between online branches of multichannel retailers and their Internet pure-play counterparts, to establish whether online pricing efficiency will weaken due to the presence of multichannel retailers. Research findings in the DVD market revealed that online branches of multichannel DVD retailers sold at 
considerably higher prices, over 14 per cent higher, than their online only rivals. ${ }^{13}$ These findings have been corroborated by Morton, Zettelmeyer and Risso whose study comparing prices of cars sold in online and conventional channels identified that, on average, online consumers paid 2 per cent less than offline consumers. ${ }^{14}$ Therefore, in developing their channel strategy, companies must give consideration to the very real consumer pricing expectations

- consumers expect prices to be competitive, whichever website they purchase from, regardless of whether the site is a pure Internet operation or an online channel as part of a wider multichannel operation.

\section{OVERCOMING TECHNOLOGY COMPLEXITY}

Technology is not the be all and end all, but it is key. Implementation of IT packages for multichannel integration projects can not only mitigate risk but can also enforce best practice. Forrester asked 50 financial services organisations what technologies they used for channel integration. Most said that they relied on off-the-shelf tools from 36 different vendors and consultants, with IBM's technology leading with 32 per cent of this vote. ${ }^{15}$ An example of this is cahoot: 'At cahoot, we want to put our customers in control. That's something IBM does for us... When a customer pays a bill via the website ... it happens automatically. We don't have armies of clerks behind the scenes re-keying data in the main banking engines. ${ }^{16}$

The aim is to implement an integration solution that will reduce the need to build custom interfaces and speed up application integration and deployment. Organisations need to employ technologies that connect customer-facing systems by uniting application and integration servers, as well as embedding process tools to codify and manage business processes. ${ }^{17}$

Technology is key to implementing an integrated channel strategy, but channel innovators may find packages are not sufficiently mature to meet their needs. ${ }^{18}$ The 'one application fits all' approach may not be the best strategy. An organisation may have to use a mix of available tools to address particular needs, using best of breed by channel and using efficient systems integration to work with channels that have established systems.

Technology can hinder a channel integration programme. No technologies are capable of everything. It is essential to involve the technical team early on, and pay careful attention to the parameters of selected technology, to avoid costly redesign of processes. The technology must not, however, be allowed to totally dictate the customer experience.

\section{ORGANISATIONAL ISSUES}

Multichannel integration requires a new organisational model - one that adapts people, processes and technology to meet this coordinated approach to channel management. Redefining the organisation, and processes and technology that support it, to meet the multichannel challenge, requires strong support from the chief executive and the senior management team. They need a clear vision of how channel integration will generate business value for the organisation and where the main changes need to be in the organisation. Decisions will need to be taken on the size of team and skills to ensure the necessary resources and flexibility. Employees must have the right skills to understand increasingly sophisticated customers, analyse customer preferences and create value from these customer relationships, 
while organisations must train their employees to develop the right skills. Organisational processes must be redefined to overcome organisational barriers, reduce operational costs, increase efficiency and improve the cross-channel customer's experience.

Hugh Wilson suggests that organisational structures can be a barrier to multichannel integration when a company is product or function-focused rather than customer-focused. He also acknowledges the need for an organisation to consider whether to 'spin out' a business by establishing a separate company to exploit a new channel. Wilson concludes that although spin-outs may be suitable where a single channel strategy is appropriate to one or more customer segments, a hybrid organisational strategy would be more appropriate, based on a multichannel integration strategy to meet the different channel needs of the company's target customer groups. ${ }^{19}$

While developing a new organisational model for multichannel integration, organisations should consider cross-channel opportunities generated through channel cooperation:

'Retailer-manufacturer relationships based on shared data, technology, and investments ... to create coordinated efforts that leverage discrete assets to better focus on the customer'. ${ }^{20}$ Thus, research showed that online cooperation of retailers with their manufacturers can enhance sales through referrals. Fifty per cent of retailers and manufacturers surveyed by Forrester said that their online sales increased by collaborating, for some by as much as 25 per cent. While online cooperation between retailers and manufacturers allows channel-hopping Internet customers a fuller product selection, it also minimises channel conflict between retailers and manufacturers. Both the manufacturer and the retailer benefit as they give each other the opportunity to increase online and offline sales by providing each other with customer referrals. 'Manufacturers will close $\$ 50$ billion in online sales ... but influence $\$ 235$ billion in other sales. The power of manufacturers online lies in their ability to affect retailers' sales, both online and offline. Consumers will take what they've learned while visiting manufacturer sites and spend almost $\$ 90$ billion online and $\$ 147$ billion in brick-and-mortar stores and catalogs' ${ }^{21}$

\section{MEASUREMENT}

An organisation is unlikely to get it right first time, so it is vital to measure, monitor and review channel integration programmes. Financial measures are important but they are a blunt instrument in a multichannel world where not all channels are used to fulfil or 'close the deal'. Instead a balanced scorecard approach is needed, in which a mixture of relevant strategic and operational measures are applied. This includes customer-focused measures, innovation and learning measures and process measures, all of which drive the financial and value measures. Profit rather than sales targeting, should be used (sales targeting focuses on promoting volume at the expense of profits and the quality of the customer base, while profit targeting focuses on contribution rather than volume and provides a basis for prioritising multichannel offers).

Consideration should be given to how to measure employees. For example, are Web and call-centre staff going to cooperate or compete if they are given independent targets? Employees should be measured on customer profitability (present or ideally estimated future), as opposed to rewards being tied to a particular channel, as this can lead to focus on maximising returns from that 
channel. A bricks and mortar employee is unlikely to divert customers to a low-cost Web channel if this reduces his or her bonus. ${ }^{22}$ Consequently, single channel metrics should be replaced with cross-channel metrics. This may include crediting one channel for purchases through another channel or rewarding different customer service representatives for their shared involvement in resolving a customer inquiry. ${ }^{23}$

\section{THE ECONOMICS OF MULTICHANNEL INTEGRATION}

Managing channels separately may not only damage customer relationships but also increase costs unnecessarily. The cost of running separate order-tracking and customer service operations, operating multiple warehouses and fulfilment systems, employing buyers and merchandisers with overlapping skills and building multiple brands is high. ${ }^{24}$ Given the potential of significant operational cost savings, the economic argument for consolidating infrastructures, management functions and technology through multichannel integration is strong. Efficiency savings will directly affect the bottom line. Integration can improve service levels but also lower cost to serve. Such cost savings may, however, require high initial investment: Forrester research into 50 financial services organisations, to determine the cost of channel synchronisation, revealed that 58 per cent of these firms believed that implementation of such an integration strategy would cost at least US $\$ 1 \mathrm{~m}$ per year with 16 per cent spending more than US $\$ 20 \mathrm{~m}$ per year. ${ }^{25}$ So, failure to plan properly may result in no cost benefit or may, at worst, actually significantly increase costs. For example, a move to self-service over the Internet may increase call-centre load and reduce profits temporarily. Consideration must be given to the costs of integrating new e-channels with 'legacy processes and systems, new fulfilment processes, origination and management of the online catalogue and supporting text and pictures and customer-service staff. ${ }^{26}$

So, companies need to ensure suitable ROI from their multichannel investments. Scenario analysis should be combined with testing and piloting where possible to develop a business case to ensure an adequate return on investment. Ultimately, channels must be used selectively, according to their strengths and customer preferences. A balance must be struck between growth, effectiveness, cost control, centralisation and channel autonomy. ${ }^{27}$

\section{RECOMMENDATIONS}

The main recommendations are that companies:

- look at what they have, they might be pleasantly surprised (rarely, if ever, can firms start with a blank sheet of paper so they must build, adapt and add to what they have)

- build a roadmap for change, not an unachievable vision: search for quick wins and prepare to be pragmatic multichannel integration projects, by their very nature, are enterprise-wide and very hard to get right

- start with rapid ROI and build: process redesign and a channel function review are good places to start to deliver significant ROI within a short time.

Hugh Wilson suggests a five-stage roadmap for formulating a multichannel strategy:

1 analyse the industry structure; use market mapping and intermediation analysis 
2 define channel chains to describe how channels combine to serve customers through their lifetime; consider both current and potential combinations and fit with customer lifecycle

3 compare value proposition; use the channel curve to test whether a channel innovation will win market acceptance

4 set channel strategies; by considering strategic options and the channel mix using the classic channel choice portfolio matrices for prioritising

5 determine channel tactics; consider organisational structure, HR and reward systems, and project management and IT. ${ }^{28}$

Alternatively, Flint and Spieler detail a four-stage process which should be followed to create a successful multichannel enterprise:

1 create a customised multichannel strategy

2 determine the relative positioning and priority for the channels

3 organise for multichannel operation reconcile the need for central control over branding and service standards with the need for local autonomy in managing individual channels

4 adopt best practices for integrating the new with the old. ${ }^{29}$

A starting point could be to transform yesterday's cost-intensive call centre into today's multichannel Customer Interaction Centre (CIC). The CIC is the first line of communication with customers and its 'hublike' quality means that all customer touch-points and departments connect to it. The solution can include call recording on a sampling basis, searchable tagging to route intelligence about customers to where it is needed most, and the ability to monitor any call at any time from any location. Another advantage is the ability to build and maintain a data-rich, 360-degree profile of each customer such that even if a customer leaves and then returns the company is able to view and maintain a complete record of the relationship. $^{30}$

Although many channel integration projects are in their infancy, with an expectation that such strategies are a long-term play, failure to act swiftly may mean that companies are left behind by the competition and exposed to the risks of inconsistent customer expectations and channel disconnect, which in turn may affect revenue and efficiency. Consumers are becoming ever more multichannel in behaviour - using specific channels at various stages of the interaction process. Consequently, companies must understand their customers' expectations, in particular their customers' interaction preferences and patterns of behaviour across different channels, particularly for those segments which are critical for the company's future. They must improve channel performance for these segments rather than trying to be all things to all customers.

Companies will find it hard to implement a fully synchronised multichannel strategy. They therefore need to undertake staged roll-outs of their multichannel strategy, while ensuring that any multichannel investments are prioritised and backed by a sound business case. Ultimately, the organisation needs to balance the goals of growth and reduced costs, and centralisation and channel autonomy.

\section{CHECKLIST}

\section{Strategy}

- what is meant by integrated channels?

- what would they look like from the 
point of view of supplier, partner and customer?

- how should how the company manages its channels vary between transactional products (where customers are in regular contact) and life-cycle products (where customers might make a decision infrequently)? What about the middle ground?

- what could be the benefits and costs of integration - for supplier, partner and customer? What are the risks of not doing it well?

- where is the business on the evolutionary path? Who is doing it well in the industry and what results are they getting? Are they focusing their attention on particular combinations of channels, particular products, particular market segments?

- what channels does the business use? Are some more important than others, and if so, why? Are any strategically more important than others?

- how many of the firm's channels are integrated, partially or completely, and across different episodes in the customer buying cycle?

- does the firm have a multichannel strategy? Has it tried to implement one before? How far did it get? If it failed, why was it?

— if a competitor introduced a brilliant new product, would they need to use an integrated channel approach, or would they use a variety of business partners to achieve communication and distribution?

- has the firm experimented with $\mathrm{x}$-channel scenarios?

- is the firm using channel functions fully?

- do the firm's existing products work across multiple channels?

- has the firm experimented with $\mathrm{x}$-channel scenarios?
- do the company's existing products work across multiple channels? Could they?

\section{Understanding customer behaviour and needs}

- who are the firm's best customers? Firms should use strong data mining tools to identify the 20 per cent of customers who use those multitouch-points and generate high value for the company and whose preferences will satisfy 80 per cent of the customer base

- what channels do each of the firm's customer segments use? Is there a clear pattern? Why do they do it?

- does the firm fully understand its customers' needs and preferences?

- how confident is the firm of its segmentation?

- does the firm's segmentation reflect failure to achieve multichannel integration?

- does the company precisely understand its target multichannel customers' preferences?

\section{Channel costs}

- does the firm know how much each of its channels costs - overall and for different kinds of transaction, for different type of customer?

- how cost effective are the firm's channels? Do they meet regulatory requirements in terms of cost effectiveness and quality?

- is the firm using its channels economically?

\section{Implementation}

- how can customer information be 
better used to improve the cross-channel customer experience?

- what is the relative importance in achieving channel integration of technology versus people and processes?

- how important is data integration, and is it possible?

— is the firm optimally organised for multichannel operation?

\section{People and organisation}

- are the firm's staff paid on performance only in the channel they work in (multichannel unfriendly targets)?

- does the firm have cross-organisational support for cross-channel scorecards and compensation?

- how can the firm allow for flexibility that might be needed immediately (for expected situations) or in the future (eg mergers and acquisitions)?

- is the firm's organisational structure optimising the benefits of channel cooperation?

\section{Measurement}

- what would a balanced multichannel scorecard look like in the firm's organisation? How would it work?

— how should customer-facing staff work with it? What about managers with accountability for different products or channels? How do the firm's processes support use of such a scorecard?

- how is the firm measuring multichannel effectiveness?

- how accurate is the firm's multichannel performance data analysis?

- do the firm's channel measures support the corporate strategy?

\section{Business case and roadmap}

- what is the case for change?

- does the firm have a business case for its multichannel programme?

- what evidence does the firm possess to prove its business case, and what evidence does it need?

- what is the firm's multichannel vision?

- what is the firm's roadmap?

- what are the risks?

- how long will it take?

- can it be phased?

- how is the firm going to achieve quick wins?

- if multichannel turns out to be infeasible or too expensive for all or part of the business, what are the options - back to product or production-centricity, finding distribution partners?

\section{References}

1 Forrester Report (2001) 'Implementing customer heuristics', April.

2 Boston Consulting Group (2001) 'The multichannel consumer', July.

3 Forrester Report (2001) 'Turning Web traffic into store sales', August.

4 Yates, S., Shevlin, R., Watson, T. and Sweeney, J. (2001) 'Integrating financial channels', Forrester Report, August.

5 Forrester Data Overview (2001) 'Retail \& media data overview'.

6 Yulinsky, C. (2002) 'Multichannel marketing Making "bricks and clicks" stick', McKinsey Marketing Practice, August.

7 Boston Consulting Group (2001) op. cit.

8 Yulinsky (2002) op. cit.

9 Ibid.

10 Williams, S., Delhagen, K., Levin, K. and Ardito, C. L. (1999) 'Synchronize channels or bust', Forrester Report, April.

11 Ibid.

12 Ibid.

13 Tang, F.-F. and Xing, X. (2001) 'Will the growth of multichannel retailing diminish the pricing efficiency of the web?', Journal of Retailing, May.

14 Morton, F. S., Zettelmeyer, F. and Risso, J. S. (2000) 'Internet car retailing', mimeo, Yale University, New Haven, CT.

15 Yates et al. (2001) op. cit.

16 Tim Sawyer, Director of Business Development and Marketing, cahoot in 'IBM multichannel 
challenge - The drive towards channel integration'.

17 Yates et al. (2001) op. cit.

18 Wilson, H. (2002) 'Multichannel integration in a digital world: A strategic approach', Cranfield School of Management.

19 Ibid.

20 Forrester Brief (2000) 'Retail ebusiness networks emerge', 7th September.

21 Zrike, S. K., Allen, L., Hamel, K., Sommer, J. and Flemming, G. (2001) 'Channel cooperation pays off', Forrester Report, May.

22 Wilson (2002) op. cit.

23 Sonderegger, P., Delhagen, K. and Dorsey, M.
(2001) 'Cross-channel scenario design', Forrester Report, September.

24 Flint, D. and Spieler, G. (2001) 'Multichannel retailing: Bringing the new into the old', Gartner, 5 th July.

25 Yates et al (2001) op. cit.

26 Flint, D. (2001) 'Questioning your multichannel strategy', Gartner, 28th June.

27 Flint and Spieler (2001) op. cit.

28 Wilson (2002) op. cit.

29 Flint and Spieler (2001) op. cit.

30 Dougherty, L. and Peck, V. (2002) 'The customer interaction center: Strategies for driving profits', Genesys, Peppers \& Rogers Group. 